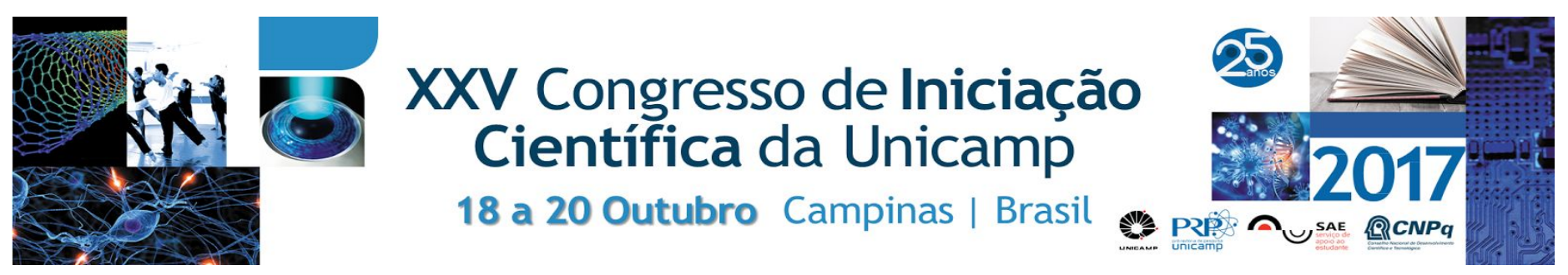

\title{
Sistema de Realidade Virtual para Apresentação de Conteúdo na Língua de Sinais Brasileira
}

\author{
Rafael Tomaz Prado*, Prof. Dr. José Mario De Martino
}

\section{Resumo}

O trabalho tem por objetivo desenvolver e avaliar sistema de realidade virtual aplicado à visualização de avatar sinalizador da Língua de Sinais Brasileira. O projeto envolveu o estudo e adaptação de sistema de apresentação de conteúdo em Libras apresentado por avatar, desenvolvido na Faculdade de Engenharia Elétrica e de Computação. O dispositivo Oculus Rift é utilizado para apresentação e criação da sensação de imersão estabelecendo ambiente de realidade virtual. A avaliação em fase final de preparação será efetuada comparativamente em relação à apresentação em um monitor convencional, levando em conta a inteligibilidade do conteúdo apresentado e a aceitação do usuário.

\section{Palavras-chave:}

Realidade Virtual, Língua de Sinais, Libras.

\section{Introdução}

Segundo o censo de 2010, cerca de 9,7 milhões de brasileiros possuem algum tipo de perda auditiva permanente ${ }^{1}$ e, destes, $30 \%$ são analfabetos. Esse alto percentual se deve, principalmente, às dificuldades enfrentadas pelas escolas. Muitas vezes não há professores capacitados e/ou intérpretes Libras para traduzir o conteúdo das disciplinas escolares.

Visando facilitar o processo de aprendizado e aumentar a interação entre estudantes surdos e ouvintes, o sistema TALES (Tecnologia Assistiva de LEitura para Surdos) propõe uma solução baseada em avatar realista para traduzir conteúdo de material didático escrito adotado nas escolas.

O objetivo do projeto é adaptar o sistema de reprodução de animações do sistema TALES de maneira a reproduzir um ambiente de realidade virtual e avaliar se há um ganho no âmbito da compreensão do sinal reproduzido pelo avatar.

\section{Resultados e Discussão}

$O$ recurso de realidade virtual foi desenvolvido utilizando o Oculus Rift ${ }^{\circledR}$ como dispositivo de reprodução gráfica. O Unity3D® foi utilizado para animar o modelo do avatar e integrar a o Rift $\circledast$ ao sistema, possibilitando a execução em Realidade Virtual.

O sistema é capaz de integrar e complementar o Projeto TALES ${ }^{2}$, utilizando o Rift $\circledast$ para aumentar a imersão dos usuários.

Uma avaliação foi elaborada em conjunto com os colaboradores do projeto TALES com o intuito de determinar se os recursos de Realidade Virtual agregam inteligibilidade ao sistema de reprodução de sinais através de avatar.

A avaliação consiste em submeter a adaptação do sistema a uma análise qualitativa feita por usuários surdos. Para isso, algumas animações foram escolhidas aleatoriamente dentre todo o repertório disponível - por volta de 150 animações gravadas - e para serem reproduzidas para os participantes utilizando o Rift@.

O formulário de questões apresentado aos usuário sudor busca avaliar o avatar sinalizador quanto à corretude gramatical, naturalidade do movimento e grau de compreensão da mensagem sinalizada. Todas as perguntas são estruturadas em escala Likert, que avalia gradativamente, em um intervalo de 1 a $5-$ em que 1 representa "ruim" e 5 representa "bom".

O material para avaliação encontra-se em fase final de preparação, não tendo ainda sido aplicado.

\section{Conclusões}

Com o sistema adaptado para utilização do recurso da realidade virtual, as noções de profundidade, sombras e animação se aproximam mais da realidade. A hipótese principal que este trabalho procura validar é que apresentação utilizando dispositivo de realidade virtual ao aumentar a sensação de imersão no ambiente virtual aumentará, em comparação à apresentação utilizando dispositivos convencionais, como monitores vídeo e telas de dispositivos móveis, a inteligibilidade da sinalização

\section{Agradecimentos}

Agradecemos à instituição PIBIC pelo apoio durante o processo de pesquisa e desenvolvimento do sistema.

Agradeço também aos professores orientadores que me guiaram durante $o$ processo de pesquisa $e$ durante o desenvolvimento do sistema, Prof. Dr. José Mario De Martino e Profa. Dra. Ivani Rodrigues da Silva, bem como à equipe do projeto TALES, utilizado como base nessa pesquisa.

\footnotetext{
Instituto Brasileiro de Geografia e Estatística - IBGE. Censo Demográfico 2010 - Características gerais da população, religião e pessoas com deficiência. Ministério do Planejamento, Orçamento e Gestão e Instituto Brasileiro de Geografia e Estatística, Rio de Janeiro, Brasil, 2010. ISSN 0104-3145.
}

${ }^{2}$ De Martino, J. M. et al. Portal do Projeto TAS (Tecnologia Assistiva para Surdos): http://www.tas.fee.unicamp.br/ (último acesso: 19 de abril de 2016) 